Article

\title{
Nitronyl Nitroxide Biradical-Based Binuclear Lanthanide Complexes: Structure and Magnetic Properties
}

\author{
Lu Xi, Jing Han, Xiaohui Huang and Licun Li * \\ Department of Chemistry, Key Laboratory of Advanced Energy Materials Chemistry, College of Chemistry, \\ Nankai University, Tianjin 300071, China; 1120170195@mail.nankan.edu.cn (L.X.); \\ 2120190703@mail.nankan.edu.cn (J.H.); 2120190704@mail.nankan.edu.cn (X.H.) \\ * Correspondence: llicun@nankai.edu.cn
}

Received: 7 September 2020; Accepted: 1 October 2020; Published: 3 October 2020

\begin{abstract}
Employing a new nitronyl nitroxide biradical NITPhPzbis(NITPhPzbis = 5-(1-pyrazolyl)-1,3bis(1'-oxyl-3'-oxido-4', 4', $5^{\prime}, 5^{\prime}$-tetramethyl-4,5-hydro- $1 H$-imidazol-2-yl)benzene), a series of $2 p$ - $4 f$ complexes $\left[\mathrm{Ln}_{2}(\mathrm{hfac})_{6}\left(\mathrm{H}_{2} \mathrm{O}\right)(\mathrm{NITPhPzbis})\right]\left(\mathrm{Ln}^{\mathrm{III}}=\mathrm{Gd} \mathbf{1}, \mathrm{Tb} 2, \mathrm{Dy} 3 ; \mathrm{hfac}=\right.$ hexafluoroacetylacetonate $)$ were successfully synthesized. In complexes 1-3, the designed biradical NITPhPzbis coordinates with two $\mathrm{Ln}^{\mathrm{III}}$ ions in chelating and bridging modes to form a four-spin binuclear structure. Direct-current magnetic study of $\mathrm{Gd}$ analogue indicates that ferromagnetic exchange exists between the Gd ion and the radical while antiferromagnetic coupling dominates between two mono-radicals. Dynamic magnetic data show that the $\chi^{\prime \prime}$ signals of complex 3 exhibit frequency dependence under zero field, demonstrating slow magnetic relaxation behavior in complex 3 . And the estimated values of $U_{\text {eff }}$ and $\tau_{0}$ are about $8.4 \mathrm{~K}$ and $9.1 \times 10^{-8} \mathrm{~s}$, respectively.
\end{abstract}

Keywords: nitronyl nitroxide biradical; lanthanide; crystal structure; slow magnetic relaxation

\section{Introduction}

In recent years, radical-lanthanide architectures have been appealing candidates for molecular nanomagnets (i.e., single-molecule magnets (SMMs) and single-chain magnets (SCMs)) due to a beneficial combination of strong magnetic anisotropy originated from lanthanide ion and effective magnetic exchange between $4 f$ ion and radical [1-12]. Using this intriguing strategy, some remarkable results have been obtained, e.g., a $\mathrm{N}_{2}{ }^{3-}$ radical-bridged binuclear Tb-SMM with a blocking temperature of $20 \mathrm{~K}$ [13]; the radical-bridged trinuclear Dy SMMs $\mathrm{Cp}_{6}{ }_{6} \mathrm{Dy}_{3}\left(\mu_{3}-\mathrm{HAN}\right)\left(\mathrm{HAN}=\right.$ hexaazatrinaphthylene; $\mathrm{Cp}^{*}=$ pentamethylcyclopentadienyl) displaying obvious hysteresis loop below 3.5 K [14]. In 2018, K. R. Dunbar et al., reported the first metallacycle $\left[\mathrm{Dy}_{3}(\mathrm{hfac})_{6}\left(\mathrm{bptz}^{-}\right)_{3}\right](\mathrm{bptz}=3,6$-bis(2-pyridyl)-1,2,4,5-tetrazine; hfac $=$ hexafluoroacetylacetonate) exhibiting temperature-dependent out-of-phase $\left(\chi^{\prime \prime}\right)$ signals in the high-frequency range [15]. Noticeable, most of radical-Ln based molecular nanomagnets are constructed using mono-radicals [3-22], and the employments of biradicals are less common [23-28]. Nitronyl nitroxide biradical-Ln approach, one hand, can result in interesting spin topology in which the unique magnetic behavior could be observed. On the other hand, intramolecular magnetic coupling may be tuned through the choice of the suitable conjugated spacer of the biradical [29]. Nitronyl nitroxide biradical-Ln strategy provides new chances for designing molecular nanomagnets. Until now, only a handful of nitronyl nitroxide biradical-Ln compounds with slow relaxation of magnetization have been reported [25-28] due to the inherent difficulties encountered during the biradical preparation [30,31]. Very recently, we reported a series of nitronyl nitroxide biradical bridged tetranuclear lanthanide 
complexes by means of a nitronyl nitroxide biradical with one flexible pyridine group [28], some of which are SMMs. Following this work, herein we designed a new nitronyl nitroxide biradical, namely, 5-(1-pyrazolyl)-1,3-bis(1'-oxyl-3'-oxido-4', 4', 5', 5' -tetramethyl-4,5-hydro-1H-imidazol-2-yl)benzene (NITPhPzbis, Scheme 1). Utilizing this biradical, a family of nitronyl nitroxide biradical bridged binuclear lanthanide complexes [Ln $\left.2(\mathrm{hfac})_{6}\left(\mathrm{H}_{2} \mathrm{O}\right)(\mathrm{NITPhPzbis})\right]\left(\mathrm{Ln}^{\mathrm{III}}=\mathrm{Gd}\right.$ 1, Tb 2, Dy 3) were fabricated. The magnetic investigations show that the exchange coupling between $\mathrm{Gd}^{\mathrm{III}}$ ion and the coordinated NO group is ferromagnetic. Moreover, the slow magnetic relaxation was found in Dy analogue.

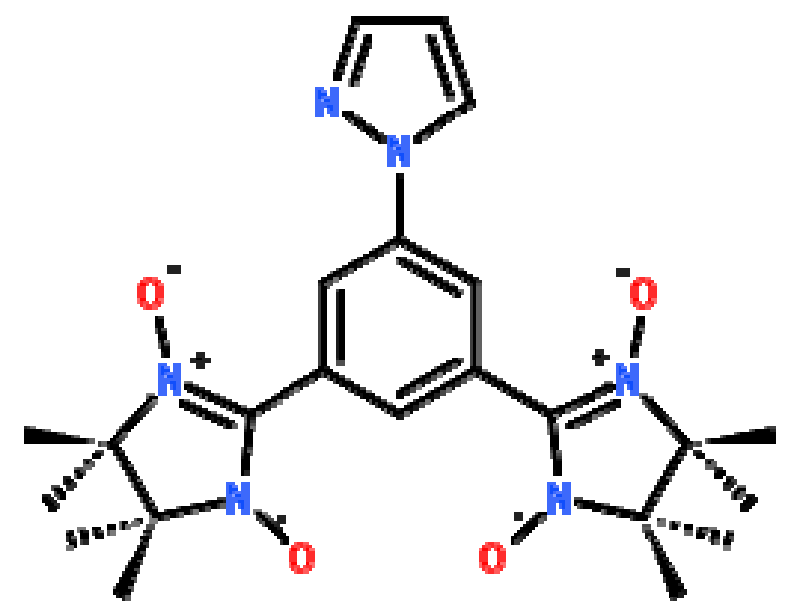

Scheme 1. NITPhPzbis ligand.

\section{Results and Discussion}

\subsection{Synthetic Aspect and Crystal Structures}

The specific synthesis process of NITPhPzbis is shown in Scheme S1. Three binuclear Ln-based complexes were successfully prepared by using NITPhPzbis. The elemental analysis results of complexes 1-3 match well with their theoretical values. To further determine the phase purity of the crystal samples, PXRD tests on complexes 1-3 were conducted (Figure S1). It can be seen that the experimental spectra are consistent with the simulated spectrum of complex 3, which provides an important guarantee for the next study of magnetic property. Figure S2 presents the IR spectra of 1-3. The peaks observed at about $1605 \mathrm{~cm}^{-1}, 1506 \mathrm{~cm}^{-1}$, and $1353 \mathrm{~cm}^{-1}$ are severally attributed to the $C=C, C=N$, and N-O stretching in the NITPhPzbis ligand while the absorption peaks at about $1648 \mathrm{~cm}^{-1}\left(v_{\mathrm{C}=\mathrm{O}}\right), 800 \mathrm{~cm}^{-1}$ $\left(\delta_{\mathrm{C}-\mathrm{O}}\right), 1247 \mathrm{~cm}^{-1}, 1131 \mathrm{~cm}^{-1}\left(v_{\mathrm{C}-\mathrm{F}}\right)$, and $658 \mathrm{~cm}^{-1}\left(\delta_{\mathrm{C}-\mathrm{F}}\right)$ originate from the co-ligand $\mathrm{hfac}^{-}$. The weak absorption bands at about $3575 \mathrm{~cm}^{-1}$ are due to the coordinated $\mathrm{H}_{2} \mathrm{O}$ molecules.

Crystallographic study proves that complexes 1-3 are isomorphous (Figure 1 and Figures S3 and S4) and all belong to the triclinic $P \overline{\mathbf{1}}$ system. The crystallographic data and refinement parameters for 1-3 are included in Table 1, and the important parameters are presented in Table 2. Here, the structure of complex 1 will be a representative for description. As shown in Figure 1a, the NITPhPzbis ligand chelates one $\mathrm{Gd}(\mathrm{hfac})_{3}$ unit through its two adjacent NO groups, and coordinates with another $\mathrm{Gd}(\mathrm{hfac})_{3}$ unit through another NO group to form a four-spin binuclear structure. Both Gd1 and $\mathrm{Gd} 2$ are in eight-coordinated environment, and the eighth coordination sphere of Gd2 is completed with a $\mathrm{H}_{2} \mathrm{O}$ molecule. There is weak hydrogen bond interaction between the pyrazolyl-N (N6) and the coordinated water molecule in which the distance of $\mathrm{O} 17_{\text {water }}(\mathrm{H}$-donor $) \cdots \mathrm{N} 6_{\text {pyrazol }}(\mathrm{H}$-acceptor $)$ is $2.811 \AA$ and the angle of $\mathrm{O} 17_{\text {water }}-\mathrm{H} \cdots \mathrm{N} 6_{\text {pyrazol }}$ is $148.91^{\circ}$. According to SHAPE analysis [32,33], the coordination geometry of Gd1 is $C_{2 \mathrm{v}}$ symmetry while that of Gd2 is $D_{2 \mathrm{~d}}$ (Figure $1 \mathrm{~b}$, Table S2). In complex 1, the bond lengths of the two $\mathrm{Gd} 1-\mathrm{O}_{\text {rad }}$ bonds are 2.383(8) $\AA$ and 2.472(7) $\AA$, respectively, and the distance of $\mathrm{Gd} 2-\mathrm{O}_{\text {rad }}$ is $2.454(7) \AA$. The bond lengths here are consistent with those existed in 
other nitronyl nitroxide biradical-Gd ${ }^{\mathrm{III}}$ complexes [26-28]. The length of the $\mathrm{Gd}-\mathrm{O}_{\mathrm{hfac}}$ bond ranges from 2.343(9) to 2.412(7) $\AA$. The bond distance of $\mathrm{Gd} 2-\mathrm{O}_{\mathrm{H} 2 \mathrm{O}}$ is $2.378(7) \AA$. The Gd1-O-N-C torsion angles are $61.3(16)^{\circ}$ and $-58.5(17)^{\circ}$, respectively, while the $\mathrm{Gd} 2-\mathrm{O}-\mathrm{N}-\mathrm{C}$ torsion angle is $-64.8(14)^{\circ}$. The two dihedral angles between benzene ring and the $\mathrm{ON}-\mathrm{C}-\mathrm{NO}$ of mono-radicals are $37.7(5)^{\circ}$ and $31.4(4)^{\circ}$ while the dihedral angle formed by pyrazole ring and benzene ring is $30.5(4)^{\circ}$. In the binuclear structure of $\mathbf{1}$, the distance between the adjacent Gd1 and Gd2 is $8.351 \AA$. Figure 2 shows the crystal packing diagram of $\mathbf{1}$. The closest separation between intermolecular $\mathrm{Gd}^{\mathrm{III}}$ ions is $6.265 \AA$, and the shortest distance between uncoordinated NO…NO is $11.976 \AA$.

(a)

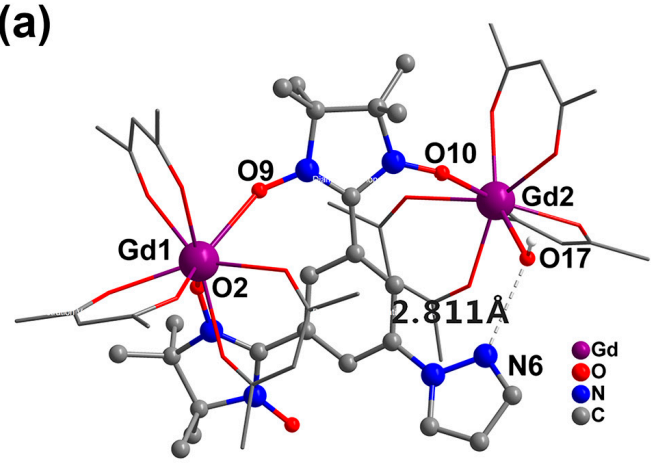

(b)

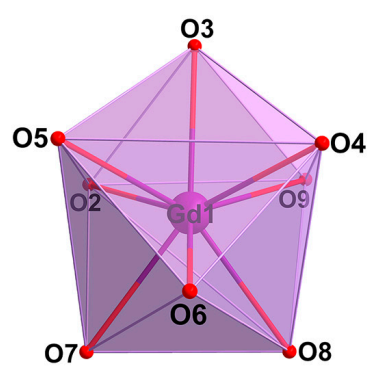

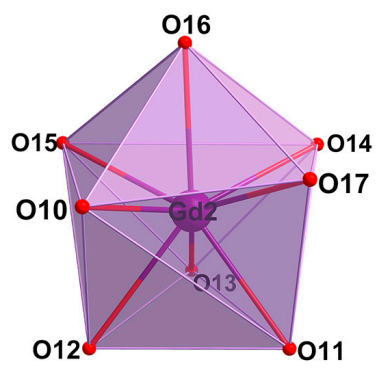

Figure 1. (a) The binuclear structure of $\mathbf{1}$ (color code: violet-Gd, gray-C, red-O, blue- $\mathrm{N}, \mathrm{H}$ and $\mathrm{F}$ atoms are omitted; There is weak hydrogen bond interaction between the pyrazolyl-N (N6 ) and the coordinated water molecule in which the distance of $\mathrm{O}_{17}$ water $\left(\mathrm{H}\right.$-donor) $\cdots \mathrm{N} 6_{\text {pyrazol }}$ (H-acceptor) is $2811 \AA$ and the angle of $\mathrm{O} 17_{\text {water }}-\mathrm{H} \cdots \mathrm{N} 6_{\text {pyrazol }}$ is $148.91^{\circ}$.). (b) Coordination polyhedra of Gd1 and $\mathrm{Gd} 2$ in 1.

Table 1. Crystallographic data and structure refinement parameters for 1-3.

\begin{tabular}{|c|c|c|c|}
\hline Complex & $1 \mathrm{Gd}$ & $2 \mathrm{~Tb}$ & 3 Dy \\
\hline Formula & $\mathrm{C}_{53} \mathrm{H}_{38} \mathrm{~F}_{36} \mathrm{Gd}_{2} \mathrm{~N}_{6} \mathrm{O}_{17}$ & $\mathrm{C}_{53} \mathrm{H}_{38} \mathrm{~F}_{36} \mathrm{~Tb}_{2} \mathrm{~N}_{6} \mathrm{O}_{17}$ & $\mathrm{C}_{53} \mathrm{H}_{38} \mathrm{~F}_{36} \mathrm{Dy}_{2} \mathrm{~N}_{6} \mathrm{O}_{17}$ \\
\hline$M, \mathrm{~g} \cdot \mathrm{mol}^{-1}$ & 2029.39 & 2032.73 & 2039.89 \\
\hline$T / K$ & $113(2)$ & $113(2)$ & $113(2)$ \\
\hline Crystal system & triclinic & triclinic & triclinic \\
\hline Space group & $P_{\overline{1}}$ & $P_{\overline{1}}$ & $P_{\overline{1}}$ \\
\hline$a / \AA$ & $11.976(2)$ & 11.997(2) & 11.997(2) \\
\hline$b / \AA$ & $13.060(3)$ & $13.050(3)$ & $13.009(3)$ \\
\hline$c / \AA$ & $26.438(5)$ & $26.470(5)$ & $26.471(5)$ \\
\hline$\alpha / \operatorname{deg}$ & $78.39(3)$ & $78.04(3)$ & $78.07(3)$ \\
\hline$\beta /$ deg & $77.93(3)$ & $77.70(3)$ & $77.76(3)$ \\
\hline$\gamma /$ deg & $64.89(3)$ & $64.80(3)$ & $64.83(3)$ \\
\hline$V / \AA^{3}$ & $3632.1(16)$ & $3631.8(16)$ & $3622.2(16)$ \\
\hline Z & 2 & 2 & 2 \\
\hline$D_{\text {calcd }} / \mathrm{g} \cdot \mathrm{cm}^{-3}$ & 1.856 & 1.859 & 1.870 \\
\hline$\mu / \mathrm{mm}^{-1}$ & 1.969 & 2.090 & 2.206 \\
\hline$\theta /$ deg & $1.588-25.009$ & 1.895-25.009 & $1.588-25.009$ \\
\hline$F(000)$ & 1972 & 1976 & 1980 \\
\hline Reflns collected & 27,871 & 30,362 & 34,633 \\
\hline Unique reflns $/ R_{\text {int }}$ & $12,651 / 0.0717$ & $12,514 / 0.0512$ & $12,738 / 0.0711$ \\
\hline $\operatorname{GOF}\left(F^{2}\right)$ & 1.078 & 1.034 & 1.019 \\
\hline$R_{1} / w R_{2}(I>2 \sigma(I))$ & $0.0717 / 0.1782$ & $0.0522 / 0.1416$ & $0.0571 / 0.1538$ \\
\hline$R_{1} / w R_{2}$ (all data) & $0.0921 / 0.2202$ & $0.0632 / 0.1509$ & $0.0737 / 0.1752$ \\
\hline
\end{tabular}

$\mathrm{R} 1=\Sigma(|| \mathrm{Fo}|-| \mathrm{Fc}||) / \Sigma|\mathrm{Fo}|, \mathrm{wR} 2=[\Sigma \mathrm{w}(|\mathrm{Fo}| 2-|\mathrm{Fc}| 2) 2 / \Sigma \mathrm{w}(|\mathrm{Fo}| 2) 2] 1 / 2$. 
Table 2. The key bond lengths $[\AA]$ and bond angles $\left[{ }^{\circ}\right]$ for $1-3$.

\begin{tabular}{cccc}
\hline Complex & $\mathbf{1 ~ G d}$ & $\mathbf{2 ~ T b}$ & 3 Dy \\
\hline & $2.383(8)$ & $2.365(5)$ & $2.352(6)$ \\
$\mathrm{Ln}-\mathrm{O}_{\mathrm{rad}}$ & $2.472(7)$ & $2.466(4)$ & $2.460(5)$ \\
& $2.454(7)$ & $2.437(4)$ & $2.429(5)$ \\
$\mathrm{Ln}-\mathrm{O}_{\mathrm{hfac}}$ & $2.343(9)-2.412(7)$ & $2.323(5)-2.399(5)$ & $2.306(6)-2.390(5)$ \\
$\mathrm{Ln}-\mathrm{O}_{\mathrm{H} 2 \mathrm{O}}$ & $2.378(7)$ & $2.373(4)$ & $2.364(5)$ \\
$\mathrm{O}_{\mathrm{rad}}-\mathrm{Ln}-\mathrm{O}_{\mathrm{rad}}$ & $82.0(3)$ & $82.34(16)$ & $82.0(2)$ \\
$\mathrm{O}_{\mathrm{rad}}-\mathrm{Ln}-\mathrm{O}_{\mathrm{H} 2 \mathrm{O}}$ & $77.7(2)$ & $77.91(15)$ & $77.69(17)$ \\
\hline
\end{tabular}

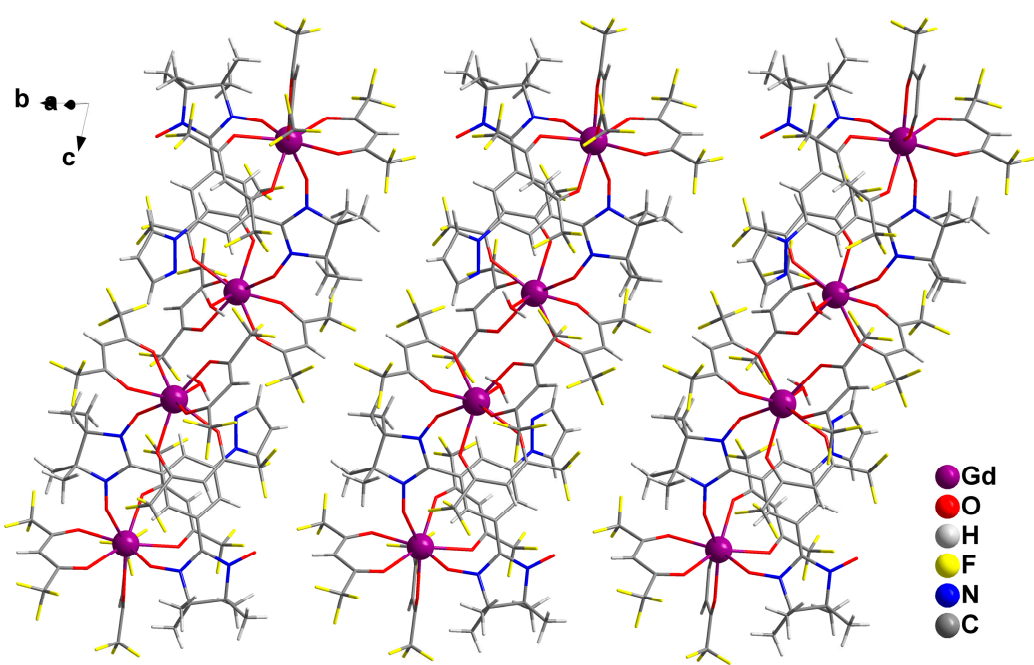

Figure 2. Crystal packing diagram of $\mathbf{1}$.

\subsection{Magnetic Properties}

The dc magnetic susceptibility data of three complexes measured in 1000 Oe magnetic field are shown in Figures 3 and 4. For complex 1, the room temperature value of $\chi_{\mathrm{M}} T$ is $16.99 \mathrm{~cm}^{3} \mathrm{Kmol}^{-1}$ (Figure 3), slightly higher than the value $\left(16.51 \mathrm{~cm}^{3} \mathrm{Kmol}^{-1}\right)$ expected for two Gd ${ }^{\mathrm{III}}$ ions (Gd ${ }^{\mathrm{III}}:{ }^{8} S_{7 / 2}$, $g=2, C=7.88 \mathrm{~cm}^{3} \mathrm{Kmol}^{-1}$ ) and two mono-radicals (radical: $S=1 / 2, g=2, C=0.375 \mathrm{~cm}^{3} \mathrm{Kmol}^{-1}$ ) which are magnetically uncorrelated. On lowering the temperature, the $\chi_{\mathrm{M}} T$ value increases steadily to a maximum of $21.35 \mathrm{~cm}^{3} \mathrm{Kmol}^{-1}$ at $2 \mathrm{~K}$, indicating that ferromagnetic exchange is dominant in the system. The field dependent magnetization curves shown in Figure 3 (inset, 2K). The observed $M$ value of $16.15 \mathrm{~N} \beta$ at $7 \mathrm{~T}$ is in agreement with the theoretical saturation value of $16 \mathrm{~N} \beta$. Based on the molecular structure, magnetic exchange pathway in $\mathbf{1}$ is shown in Scheme 2, in which $J_{1}$ is the exchange coupling between the $\mathrm{Gd}^{\mathrm{III}}$ ion and the ligated $\mathrm{NO}$ group and $J_{2}$ represents the magnetic coupling between two mono-radicals through the $\mathrm{Gd}^{\mathrm{III}}$ ion and/or $m$-phenylene ring.

A quantitative analysis has been performed using PHI software [34,35]. The spin Hamiltonian of this system is $H=-2 J_{1}\left(\hat{S}_{G d 2} \hat{S}_{r a d 1}+\hat{S}_{r a d 1} \hat{S}_{G d 1}+\hat{S}_{G d 1} \hat{S}_{r a d 2}\right)-2 J_{2}\left(\hat{S}_{r a d 1} \hat{S}_{r a d 2}\right)$. The experimental dc susceptibility and magnetization data can be well reproduced and the best fitting parameters are $g_{\text {rad }}=2.00$ (fixed), $g_{\mathrm{Gd}}=2.02, J_{1}=0.74 \mathrm{~cm}^{-1}$, and $J_{2}=-3.24 \mathrm{~cm}^{-1}$. The observed Gd-NO ferromagnetic exchange is expected, which can be ascribed to the electron transfer from $\pi^{*}$ orbital of the nitronyl nitroxide radical to $6 s / 5 d$ empty orbitals of $\mathrm{Gd}^{\mathrm{III}}$ ion $[36,37]$. The obtained magnitude of $J_{1}$ is comparable with those in other Gd-nitronyl nitroxide complexes [38]. For $J_{2}$, two kinds of magnetic pathways are active: one is via the $\mathrm{Gd}^{\mathrm{III}}$ ion, in which antiferromagnetic coupling is usually generated [39]; the other is through $m$-phenylene ring, which results in ferromagnetic interaction based on spin polarization mechanism [29] (Scheme 3). Consequently, the observed negative $J_{2}$ value is the competitive result of these two kinds of magnetic exchange, implying that antiferromagnetic exchange dominates here; this phenomenon has been observed in the similar biradical-Gd 
compounds [40]. It should be noted that the Gd-NO and NO-NO magnetic interactions observed here are weaker than those in the tetranuclear $\left[\mathrm{Gd}_{4}(\mathrm{hfac})_{12}(\mathrm{NITPhO}-3 \text { Pybis })_{2}\right](\mathrm{NITPhO}-3$ Pybis $=$ 5-(3-pyridinyloxy)-1,3-bis(1'-oxyl-3'-oxido-4', $4^{\prime}, 5^{\prime}, 5^{\prime}$-tetramethyl-4,5-hydro-1H-imidazol-2-yl) [28] that contains similar NIT bridged Ln dimer and these can be attributed the differences of $\mathrm{Gd}-\mathrm{O}-\mathrm{N}-\mathrm{C}$ torsion angles $\left(61.3(16)^{\circ},-58.5(17)^{\circ}\right.$ and $-64.8(14)^{\circ}$ for 1 and $-60.2(15)^{\circ}, 59.5(14)^{\circ}$, and $-135.0(13)^{\circ}$ for Gd4) in these two complexes which can affect the magnetic exchange between the Gd ion and NO unit [41].

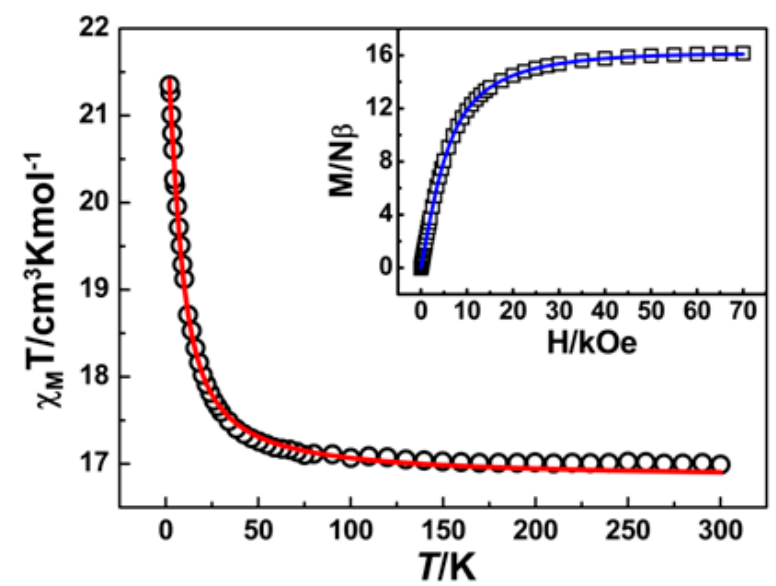

Figure 3. $\chi_{\mathrm{M}} T$ vs. $T$ curve for 1 ; Inset: $M$ vs. $H$ plot for $\mathbf{1}$ at $2 \mathrm{~K}$ (red-line and blue-line: best fitted curves by PHI).

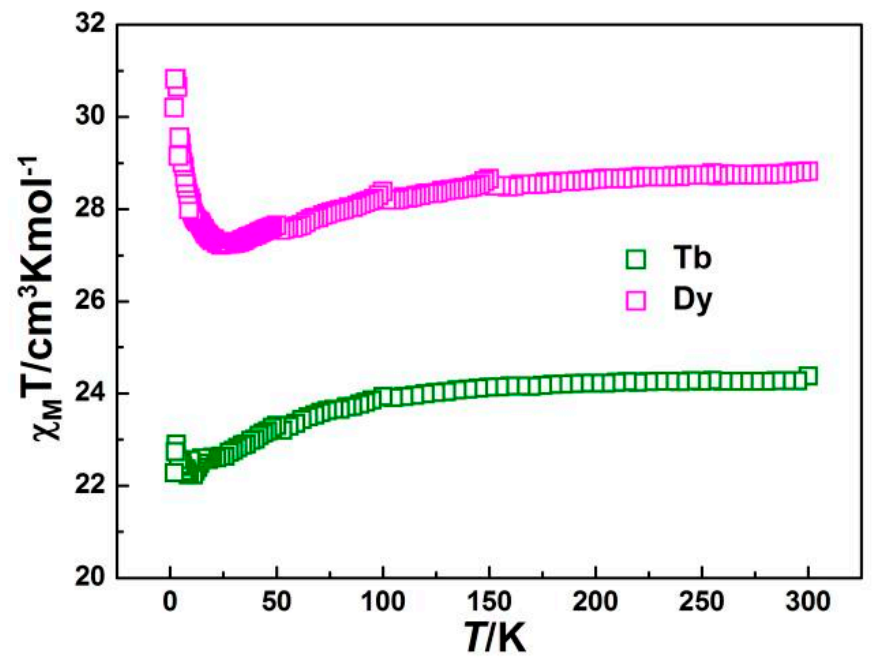

Figure 4. $\chi_{\mathrm{M}} T$ vs. $T$ curves for compounds 2 and 3.

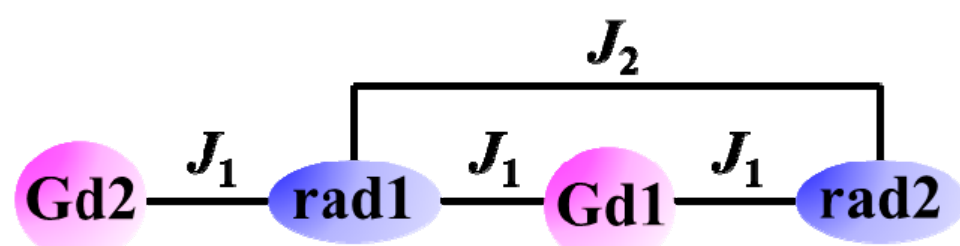

Scheme 2. Scheme 2. Magnetic communications in complex 1. 


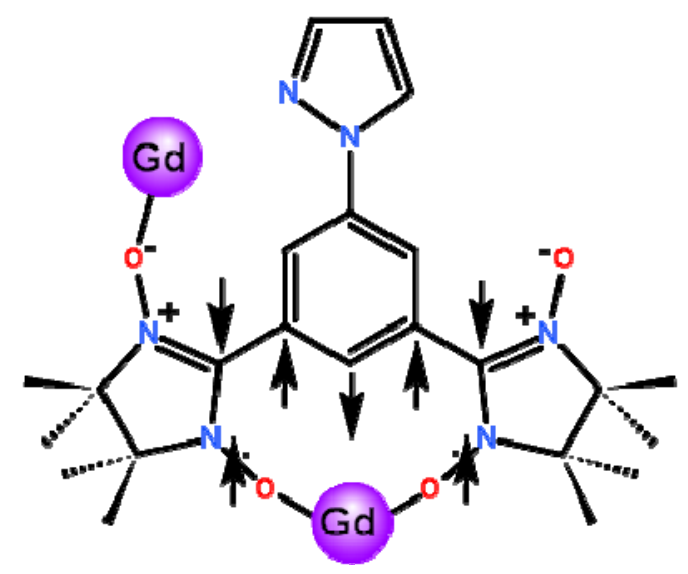

Scheme 3. Spin polarization mechanism for the magnetic coupling mediated by $m$-phenylene ring between two mono-radicals.

For complexes 2 and 3, the found $\chi_{\mathrm{M}} T$ values at $300 \mathrm{~K}$ is 24.37 and $28.81 \mathrm{~cm}^{3} \mathrm{Kmol}^{-1}$ (Figure 4), respectively, which is close to the theoretical values $\left(24.39 \mathrm{~cm}^{3} \mathrm{Kmol}^{-1}\right.$ for 2 and $29.09 \mathrm{~cm}^{3} \mathrm{Kmol}^{-1}$ for 3$)$ reckoned from an uncoupled system consisting of two $\mathrm{Ln}^{\mathrm{III}}$ ions ( $\mathrm{Tb}^{\mathrm{III}}:{ }^{7} F_{6}, g=3 / 2, \mathrm{C}=11.82 \mathrm{~cm}^{3} \mathrm{Kmol}^{-1}$; Dy III: ${ }^{6} H_{15 / 2}, g=4 / 3, C=14.17 \mathrm{~cm}^{3} \mathrm{Kmol}^{-1}$ ) and two mono-radicals (one radical: $S=1 / 2, g=2$, $C=0.375 \mathrm{~cm}^{3} \mathrm{Kmol}^{-1}$ ). For both complexes, the value of $\chi_{\mathrm{M}} T$ gradually declines when the temperature is lowered, reaching the minimum values of $22.23 \mathrm{~cm}^{3} \mathrm{Kmol}^{-1}$ at $9 \mathrm{~K}$ for 2 and $27.22 \mathrm{~cm}^{3} \mathrm{Kmol}^{-1}$ at $24 \mathrm{~K}$ for 3, which is most probably governed by the depopulation of the $\mathrm{Tb}^{\mathrm{III}}$ or Dy ${ }^{\mathrm{III}}$ ions Stark levels. Then upon further cooling, the $\chi_{\mathrm{M}} T$ value rapidly increases to the maxima of $22.91 \mathrm{~cm}^{3} \mathrm{Kmol}^{-1}$ at $3 \mathrm{~K}$ for 2 and $30.20 \mathrm{~cm}^{3} \mathrm{Kmol}^{-1}$ at $2 \mathrm{~K}$ for 3, which can be attributed to the ferromagnetic $\mathrm{NO}-\mathrm{Tb} / \mathrm{Dy}$ interaction. For 2, below $3 \mathrm{~K}$, the $\chi_{\mathrm{M}} T$ value decreases rapidly and reaches a value of $22.28 \mathrm{~cm}^{3} \mathrm{Kmol}^{-1}$ at $2 \mathrm{~K}$. The $M$ versus $H$ curves in the $0-8 \mathrm{~T}$ field range at $2 \mathrm{~K}$ for complexes 2 and 3 are depicted in Figures S7 and S8. The $M$ value is $12.72 \mathrm{~N} \beta$ and $12.57 \mathrm{~N} \beta$ at $8 \mathrm{~T}$ for 2 and 3, respectively, which is lower than expected saturation value, suggesting the presence of a significant magnetic anisotropy in the systems $[42,43]$.

Due to the presence of magnetic anisotropic $\mathrm{Tb}^{\mathrm{III}}$ or Dy ${ }^{\mathrm{III}}$ ions in complexes $\mathbf{2}$ and $\mathbf{3}$, spin dynamic properties were studied using ac susceptibility measurements under zero dc field. As displayed in Figure S9 and Figure 5, there is no non-zero out-of-phase signal for complex 2 while complex 3 exhibits clear temperature-dependent $\chi$ " components, indicating slow relaxation of magnetization behavior in 3. However, no visible peaks of the $\chi^{\prime \prime}$ signals are found for complex 3, which can be attributed to the fast quantum tunneling of magnetization (QTM) [44,45]. Accordingly, frequency-dependent ac magnetic susceptibilities for 3 were investigated at $2 \mathrm{~K}$ under dc field range of 200-4900 Oe to determine the optimized external field for suppressing the QTM. As seen, no maxima of $\chi^{\prime \prime}(v)$ components can be observed in the measurement window of our apparatus (Figure S11), suggesting that the QTM cannot be effectively suppressed in the applied dc field, thus the optimum dc field cannot be achieved. To obtain the estimation of reversal barrier $\left(U_{\text {eff }}\right)$ and characteristic relaxation time $\left(\tau_{0}\right)$, the equation $\ln \left(\chi^{\prime \prime} / \chi^{\prime}\right)=\ln \left(\omega \tau_{0}\right)+U_{e f f} / k_{B} T$ proposed by J. Bartolomé et al. [46,47] was employed. The best fitting afforded $U_{\text {eff }} \approx 8.4 \mathrm{~K}$ and $\tau_{0} \approx 9.1 \times 10^{-8} \mathrm{~s}$ (Figure $5 \mathrm{~b}$ ) which is in line with the expected characteristic relaxation time $10^{-6}-10^{-11} \mathrm{~s}$ for SMMs [48]. In order to explain the dynamic magnetic behavior of complex 3, magnetic axis directions of Dy1 and Dy2 centers in the binuclear structure were analyzed using the Magellan program [49]. Easy axes on the two DyIII ions are obviously unparallel (Figure 6); an angle of $87.65^{\circ}$ is formed between them. This angle is not conducive to the formation of large anisotropy in the system, which may be the reason for the poor magnetic relaxation behavior of $3[50,51]$. As seen, the previously reported tetranuclear [Dy ${ }_{4}(\mathrm{hfac})_{12}(\mathrm{NITPhO}-3 \mathrm{Pybis})_{2}$ ] complex presents superior slow magnetic relaxation behavior than the present $\left[\mathrm{Dy}_{2}(\mathrm{hfac})_{6}\left(\mathrm{H}_{2} \mathrm{O}\right)(\mathrm{NITPhPzbis})\right]$ complex, which should be attributed to the different 
coordination environments of Dy ions in the two compounds. The coordination geometries of Dy ions are ascertained as $C_{2 \mathrm{v}}$ and $D_{2 \mathrm{~d}}$ in [Dy $\left.2(\mathrm{hfac})_{6}\left(\mathrm{H}_{2} \mathrm{O}\right)(\mathrm{NITPhPzbis})\right]$ while those as $C_{2 \mathrm{v}}$ and $D_{4 \mathrm{~d}}$ in $\left[\mathrm{Dy}_{4}(\mathrm{hfac})_{12}(\mathrm{NITPhO}-3 \mathrm{Pybis})_{2}\right]$. As known, $\mathrm{D}_{4 \mathrm{~d}}$ symmetry is in favor of suppressing QTM effect, thus resulting in different magnetic relaxation [52].
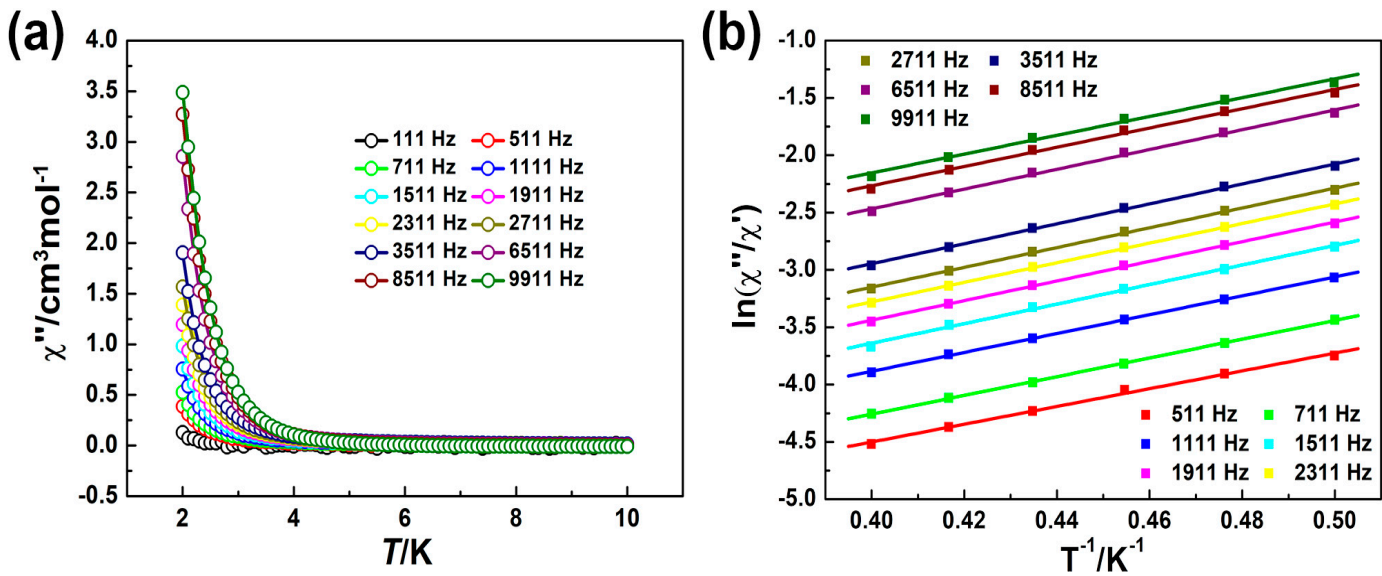

Figure 5. (a) Temperature-dependent $\chi^{\prime \prime}$ signals for 3 at zero dc field. (b) The $\ln \left(\chi^{\prime \prime} / \chi^{\prime}\right)$ vs. 1/T graph for 3 (solid lines: fitting results).

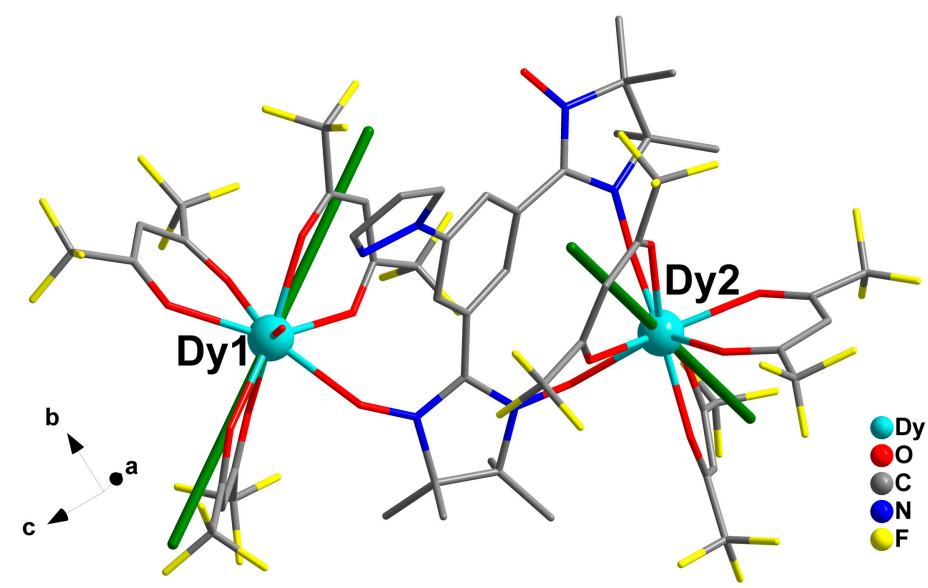

Figure 6. Magellan predicted magnetic anisotropy axes (green-rods) on Dy ${ }^{\mathrm{III}}$ centers in complex 3.

\section{Experimental Section}

\subsection{Materials and Characterizations}

The nitronyl nitroxide biradical NITPhPzbis and $\mathrm{Ln}(\mathrm{hfac})_{3} \cdot 2 \mathrm{H}_{2} \mathrm{O}$ were obtained according to literature methods [53-56]. The C, N, H content analyses for complexes 1-3 were completed on a Perkin-Elmer 240 elemental analyzer. A Bruker-Vector 22 Spectrometer was employed to collect the IR spectra of all complexes between $4000-400 \mathrm{~cm}^{-1}$. The PAN alytical X'Pert Powder X-ray diffractometer $(\mathrm{Cu} / \mathrm{K} \alpha$ radiation, $40 \mathrm{kV} \times 30 \mathrm{~mA})$ was used to record the PXRD data of $\mathbf{1}-\mathbf{3}$ at room temperature. Magnetic studies of all complexes were conducted on a Quantum Design SQUID VSM and a PPMS magnetometer. Diamagnetic contributions were estimated using Pascal's constants [57].

\subsection{Preparation of $\left[\mathrm{Ln}_{2}(h f a c)_{6}\left(\mathrm{H}_{2} \mathrm{O}\right)(\mathrm{NITPhPzbis})\right]$}

The specific process was as follows: a solution of $\mathrm{Ln}(\mathrm{hfac})_{3} \cdot 2 \mathrm{H}_{2} \mathrm{O}(0.02 \mathrm{mmol})$ in $n$-heptane $(20 \mathrm{~mL})$ was refluxed with stirring for $6 \mathrm{~h}$. Subsequently, $10 \mathrm{~mL} \mathrm{CH}_{2} \mathrm{Cl}_{2}$ solution containing $0.0045 \mathrm{~g}$ (0.01 mmol) NITPhPzbis ligand was slowly added. After refluxing for $25 \mathrm{~min}$, the mixture was 
cooled and filtered, and the filtrate was left to evaporate at room temperature. About 5-6 days later, dark-purple block-like crystals were isolated.

[Gd $\left.\mathrm{G}_{2}(\mathrm{hfac})_{6}\left(\mathrm{H}_{2} \mathrm{O}\right)(\mathrm{NITPhPzbis})\right](\mathbf{1}): \mathrm{C}_{53} \mathrm{H}_{38} \mathrm{~F}_{36} \mathrm{Gd}_{2} \mathrm{~N}_{6} \mathrm{O}_{17}$; Yield 51\%; Elem. Anal. (\%) found (calcd): C, 31.32 (31.37); N, $4.06(4.14) ; \mathrm{H}, 1.59$ (1.89). FT-IR ( $\left.\mathrm{cm}^{-1}\right)$ : 3575(w), $1648(\mathrm{~s}), 1605(\mathrm{~m}), 1506$ (m), $1353(\mathrm{~m}), 1247(\mathrm{~s}), 1131$ (s), $952(\mathrm{~m}), 896(\mathrm{~m}), 870(\mathrm{~m}), 800(\mathrm{~s}), 761$ (m), $658(\mathrm{~s}), 583(\mathrm{~s}), 544(\mathrm{~m})$ (Figure S2).

[Tb $\mathrm{Tb}_{2}$ (hfac) $\left.)_{6}\left(\mathrm{H}_{2} \mathrm{O}\right)(\mathrm{NITPhPzbis})\right](2): \mathrm{C}_{53} \mathrm{H}_{38} \mathrm{~F}_{36} \mathrm{~Tb}_{2} \mathrm{~N}_{6} \mathrm{O}_{17}$; Yield 52\%; Elem. Anal. (\%) found (calcd): C, 31.30 (31.32); N, 4.07 (4.13); H, 1.49 (1.88). FT-IR ( $\left.\mathrm{cm}^{-1}\right)$ : 3575(w), 1647 (s), 1605 (m), 1506 (m), $1354(\mathrm{~m}), 1249(\mathrm{~s}), 1131(\mathrm{~s}), 954(\mathrm{~m}), 897(\mathrm{~m}), 872(\mathrm{~m}), 802(\mathrm{~s}), 762(\mathrm{~m}), 659(\mathrm{~s}), 583(\mathrm{~s}), 546(\mathrm{~m})$ (Figure S2).

[Dy 2 (hfac) $\left.)_{6}\left(\mathrm{H}_{2} \mathrm{O}\right)(\mathrm{NITPhPzbis})\right]$ (3): $\mathrm{C}_{53} \mathrm{H}_{38} \mathrm{~F}_{36} \mathrm{Dy}_{2} \mathrm{~N}_{6} \mathrm{O}_{17}$; Yield 54\%; Elem. Anal. (\%) found (calcd): C, 31.37 (31.21); N, 4.01 (4.12); H, 2.21 (1.88). FT-IR( $\left.\mathrm{cm}^{-1}\right)$ : 3575(w), 1648 (s), $1606(\mathrm{~m}), 1505$ (m), $1354(\mathrm{~m}), 1248(\mathrm{~s}), 1130(\mathrm{~s}), 952(\mathrm{~m}), 896(\mathrm{~m}), 871(\mathrm{~m}), 800(\mathrm{~s}), 761(\mathrm{~m}), 658(\mathrm{~s}), 584(\mathrm{~s}), 545(\mathrm{~m})$ (Figure S2).

\subsection{X-ray Crystallography}

Crystal diffraction data of 1-3 were collected on a Rigaku Saturn CCD X-ray diffractometer (Mo-K $\alpha, \lambda=0.71073 \AA$ ) with a scanning mode of $\omega-\varphi$ and a test temperature of 113(2) K. Direct methods were utilized to solve crystal structures of 1-3 using SHELXS-2014 and SHELXL-2014 [58,59]. All non-H atoms were refined anisotropically, and the $\mathrm{H}$ atom positions were given geometrically. To rationalize some disordered $\mathrm{F}$ and $\mathrm{C}$ atoms on the $\mathrm{hfac}^{-}$co-ligand, commands of ISOR, SIMU, and DELU were used.

\section{Conclusions}

In this contribution, three novel biradical Ln-based complexes have been successfully prepared by utilizing the 5-(1-pyrazolyl) phenyl modified nitronyl nitroxide biradical NITPhPzbis. Complexes 1-3 feature a four-spin binuclear structure in which the NITPhPzbis serves as a bridging and chelating ligand. Magnetic studies show that complex 3 exhibits obvious slow magnetic relaxation behavior. The nitronyl nitroxide radical-Ln complex has long been an attractive strategy for constructing molecular nanomagnets. But research on nitronyl nitroxide biradical-Ln chemistry is still limited. This work discloses that nitronyl nitroxide biradical is effective building block for constructing Ln-based complexes. In the follow-up work, we will try to develop novel molecular magnetic materials presenting intriguing topologies and magnetic properties by changing the functional group in biradical and/or introducing $3 d$ spin.

Supplementary Materials: The following are available online at http://www.mdpi.com/2312-7481/6/4/48/s1, Tables S1 and S2: Selected bond lengths [ $\AA \AA]$, bond angles $\left[{ }^{\circ}\right]$ and SHAPE analyses for LnIII ions in complexes 1-3; Scheme S1: Synthesis of NITPhPzbis ligand; Figure S1: PXRD patterns for 1-3 at room temperature; Figure S2: IR spectra for 1-3; Figures S3 and S4: Binuclear structure of 2-3 and coordination polyhedra of LnIII in 2-3; Figures S5 and S6: Crystal packing diagram of 2-3; Figures S7 and S8: $\mathrm{M}$ vs. H plots for 2-3 at $2 \mathrm{~K}$; Figure S9: Temperature dependencies of $\chi^{\prime}$ and $\chi^{\prime \prime}$ for 2 in zero dc field; Figure S10: Temperature dependency of $\chi^{\prime}$ for 3 in zero dc field; Figure S11: Frequency dependencies of $\chi^{\prime}$ and $\chi^{\prime \prime}$ for 3 in the dc fields of 200-4900 Oe. Crystallographic data for 1-3 (CIF); CCDC 2027496-2027498 include the complementary crystallographic data and relevant data can be obtained by www.ccdc.cam.ac.uk/data_request/cif.

Author Contributions: L.L. and L.X. designed the study. L.X. performed the experiments and wrote the paper. L.X., J.H., X.H. and L.L. performed the magnetic data analysis and revised the paper. All authors have read and agreed to the published version of the manuscript.

Funding: This work was supported by the National Natural Science Foundation of China (Nos. 21773122 and 21471083).

Acknowledgments: L.C. Li thanks the National Natural Science Foundation of China.

Conflicts of Interest: There are no conflicts to declare.

\section{References}

1. Demir, S.; Jeon, I.-R.; Long, J.R.; Harris, T.D. Radical Ligand-Containing Single-Molecule Magnets. Coord. Chem. Rev. 2015, 289, 149-176. [CrossRef] 
2. Woodruff, D.N.; Winpenny, R.E.P.; Layfield, R.A. Lanthanide Single-Molecule Magnets. Chem. Rev. 2013, 113, 5110-5148. [CrossRef] [PubMed]

3. Rinehart, J.D.; Fang, M.; Evans, W.J.; Long, J.R. A $\mathrm{N}_{2}{ }^{3}$-Radical-Bridged Terbium Complex Exhibiting Magnetic Hysteresis at 14 K. J. Am. Chem. Soc. 2011, 133, 14236-14239. [CrossRef] [PubMed]

4. Demir, S.; Zadrozny, J.M.; Nippe, M.; Long, J.R. Exchange Coupling and Magnetic Blocking in Bipyrimidyl Radical-Bridged Dilanthanide Complexes. J. Am. Chem. Soc. 2012, 134, 18546-18549. [CrossRef] [PubMed]

5. Fatila, E.M.; Rouzieres, M.; Jennings, M.C.; Lough, A.J.; Clérac, R.; Preuss, K.E. Fine-Tuning the Single-Molecule Magnet Properties of a [Dy(III)-Radical $]_{2}$ Pair. J. Am. Chem. Soc. 2013, 135, 9596-9599. [CrossRef] [PubMed]

6. Demir, S.; Nippe, M.; Gonzalez, M.I.; Long, J.R. Exchange Coupling and Magnetic Blocking in Dilanthanide Complexes Bridged by the Multi-Electron Redox-Active Ligand 2,3,5,6-Tetra(2-Pyridyl)Pyrazine. Chem. Sci. 2014, 5, 4701-4711. [CrossRef]

7. Guo, F.-S.; Layfield, R.A. Strong Direct Exchange Coupling and Single-Molecule Magnetism in Indigo-Bridged Lanthanide Dimers. Chem. Commun. 2017, 53, 3130-3133. [CrossRef] [PubMed]

8. Zhang, P.; Perfetti, M.; Kern, M.; Hallmen, P.P.; Ungur, L.; Lenz, S.; Ringenberg, M.R.; Frey, W.; Stoll, H.; Rauhut, G.; et al. Exchange Coupling and Single Molecule Magnetism in Redox-Active Tetraoxolene-Bridged Dilanthanide Complexes. Chem. Sci. 2017, 9, 1221-1230. [CrossRef]

9. Poneti, G.; Bernot, K.; Bogani, L.; Caneschi, A.; Sessoli, R.; Wernsdorfer, W.; Gatteschi, D. A Rational Approach to the Modulation of the Dynamics of the Magnetisation in a Dysprosium?Nitronyl-Nitroxide Radical Complex. Chem. Commun. 2007, 1807. [CrossRef]

10. Rinehart, J.D.; Fang, M.; Evans, W.J.; Long, J.R. Strong Exchange and Magnetic Blocking in N23-Radical-Bridged Lanthanide Complexes. Nat. Chem. 2011, 3, 538-542. [CrossRef]

11. Pointillart, F.; Le Guennic, B.; Golhen, S.; Cador, O.; Ouahab, L.S. Low Magnetic Relaxation in Radical Cation Tetrathiaful Valene-Based Lanthanide(III) Dinuclear Complexes. Chem. Commun. 2013, 49, 11632-11634. [CrossRef] [PubMed]

12. Dolinar, B.S.; Gómez-Coca, S.; Alexandropoulos, D.I.; Dunbar, K.R. An Air Stable Radical-Bridged Dysprosium Single Molecule Magnet and Its Neutral Counterpart: Redox Switching of Magnetic Relaxation Dynamics. Chem. Commun. 2017, 53, 2283-2286. [CrossRef] [PubMed]

13. Demir, S.; Gonzalez, M.I.; Darago, L.E.; Evans, W.J.; Long, J.R. GIant Coercivity and High Magnetic Blocking Temperatures for $\mathrm{N}_{2}{ }^{3}$-Radical-Bridged Dilanthanide Complexes Upon Ligand Dissociation. Nat. Commun. 2017, 8, 2144. [CrossRef] [PubMed]

14. Gould, C.A.; Darago, L.E.; Gonzalez, M.I.; Demir, S.; Long, J.R. A Trinuclear Radical-Bridged Lanthanide Single-Molecule Magnet. Angew. Chem. Int. Ed. 2017, 56, 10103-10107. [CrossRef] [PubMed]

15. Dolinar, B.S.; Alexandropoulos, D.I.; Vignesh, K.R.; James, T.; Dunbar, K.R. Lanthanide Triangles Supported by Radical Bridging Ligands. J. Am. Chem. Soc. 2018, 140, 908-911. [CrossRef] [PubMed]

16. Lopez, N.; Prosvirin, A.V.; Zhao, H.; Wernsdorfer, W.; Dunbar, K.R. Heterospin Single-Molecule Magnets Based on Terbium Ions and $\mathrm{TCNQF}_{4}$ Radicals: Interplay between Single-Molecule Magnet and Phonon Bottleneck Phenomena Investigated by Dilution Studies. Chem. Eur. J. 2009, 15, 11390-11400. [CrossRef] [PubMed]

17. Xu, J.X.; Ma, Y.; Liao, D.Z.; Xu, G.F.; Tang, J.; Wang, C.; Zhou, N.; Yan, S.P.; Cheng, P.; Li, L.C. Four New Lanthanide-Nitronyl Nitroxide (LnIII = PrIII, SmIII, EuIII, TmIII) Complexes and a TbIII Complex Exhibiting Single-Molecule Magnet Behavior. Inorg. Chem. 2009, 48, 8890-8896. [CrossRef]

18. Pointillart, F.; Bernot, K.; Poneti, G.; Sessoli, R. Crystal Packing Effects on the Magnetic Slow Relaxation of Tb(III)-Nitronyl Nitroxide Radical Cyclic Dinuclear Clusters. Inorg. Chem. 2012, 51, 12218-12229. [CrossRef]

19. Meihaus, K.R.; Corbey, J.F.; Fang, M.; Ziller, J.W.; Long, J.R.; Evans, W.J. Influence of an Inner-Sphere K ${ }^{+}$ Ion on the Magnetic Behavior of $\mathrm{N}_{2}{ }^{3}$-Radical-Bridged Dilanthanide Complexes Isolated Using an External Magnetic Field. Inorg. Chem. 2014, 53, 3099-3107. [CrossRef]

20. Chen, P.Y.; Wu, M.Z.; Li, T.; Shi, X.J.; Tian, L.; Liu, Z.Y. Lanthanide Tetranuclear Cage and Mononuclear Cocrystalline Nitronyl Nitroxide Complex with Single-Molecule-Magnet Behavior. Inorg. Chem. 2018, 57, 12466-12470. [CrossRef]

21. Sun, J.; Sun, Z.; Li, L.; Sutter, J.P. Lanthanide-Nitronyl Nitroxide Chains Derived from Multidentate Nitronyl Nitroxides. Inorg. Chem. 2018, 57, 7507-7511. [CrossRef] [PubMed] 
22. Xi, L.; Sun, J.; Li, H.; Han, J.; Huang, X.; Li, L. Chain versus Discrete Assembly of Nitronyl Nitroxide Radical-Lanthanide Complexes: Regulating Magnetization Dynamics by Modifying Coordination Symmetry. Cryst. Growth Des. 2020, 20, 3785-3794. [CrossRef]

23. Wang, K.; Qi, D.; Wang, H.; Cao, W.; Li, W.; Liu, T.; Duan, C.; Jiang, J. Binuclear Phthalocyanine-Based Sandwich-Type Rare Earth Complexes: Unprecedented Two $\pi$-Bridged Biradical-Metal Integrated SMMs. Chem. Eur. J. 2013, 19, 11162-11166. [CrossRef] [PubMed]

24. Morita, T.; Damjanović, M.; Katoh, K.; Kitagawa, Y.; Yasuda, N.; Lan, Y.; Wernsdorfer, W.; Breedlove, B.K.; Enders, M.; Yamashita, M. Comparison of the Magnetic Anisotropy and Spin Relaxation Phenomenon of Dinuclear Terbium(III) Phthalocyaninato Single-Molecule Magnets Using the Geometric Spin Arrangement. J. Am. Chem. Soc. 2018, 140, 2995-3007. [CrossRef]

25. Bernot, K.; Pointillart, F.; Rosa, P.; Etienne, M.; Sessoli, R.; Gatteschi, D. Single Molecule Magnet Behaviour in Robust Dysprosium-Biradical Complexes. Chem. Commun. 2010, 46, 6458. [CrossRef]

26. Li, X.; Li, T.; Tian, L.; Liu, Z.-Y.; Wang, X.G. A Family of Rare Earth Complexes with Chelating Furan Biradicals: Syntheses, Structures and Magnetic Properties. RSC Adv. 2015, 5, 74864-74873. [CrossRef]

27. Li, H.; Sun, J.; Yang, M.; Sun, Z.; Xie, J.; Ma, Y.; Li, L. Functionalized Nitronyl Nitroxide Biradical Bridged One-Dimensional Lanthanide Chains: Slow Magnetic Relaxation in the Tb and Dy Analogues. New J. Chem. 2017, 41, 10181-10188. [CrossRef]

28. Xi, L.; Li, H.; Sun, J.; Ma, Y.; Tang, J.; Li, L. Designing Multicoordinating Nitronyl Nitroxide Radical Toward Multinuclear Lanthanide Aggregates. Inorg. Chem. 2019, 59, 443-451. [CrossRef]

29. Catala, L.; Le Moigne, J.; Kyritsakas, N.; Rey, P.; Novoa, J.J.; Turek, P. Towards a Better Understanding of the Magnetic Interactions withinm-Phenylene $\alpha$-Nitronyl Imino Nitroxide Based Biradicals. Chem. Eur. J. 2001, 7, 2466-2480. [CrossRef]

30. Luneau, D.; Laugier, J.; Rey, P.; Ulrich, G.; Ziessel, R.; Legoll, P.; Drillon, M. Synthesis, Coordination and Magnetic Properties of a Novel Family of Stable Chelate Based Biradicals: Molecular Structure of a 2,2'-Bipyridine N-Oxide N-Oxyl Biradical and Its Copper(II) Complex. J. Chem. Soc. Chem. Commun. 1994, 6, 741. [CrossRef]

31. Caneschi, A.; Chiesi, P.; David, L.; Ferraro, F.; Gatteschi, D.; Sessoli, R. Crystal Structure and Magnetic Properties of Two Nitronyl Nitroxide Biradicals and of Their Copper(II) Complexes. Inorg. Chem. 1993, 32, 1445-1453. [CrossRef]

32. Casanova, D.; Llunell, M.; Alemany, P.; Álvarez, S. The Rich Stereochemistry of Eight-Vertex Polyhedra: A Continuous Shape Measures Study. Chem. Eur. J. 2005, 11, 1479-1494. [CrossRef] [PubMed]

33. Llunell, M.; Casanova, D.; Cirera, J.; Alemany, P.; Alvarez, S. SHAPE 2.1; University of Barcelona: Barcelona, Spain, 2013.

34. Chilton, N.F.; Anderson, R.; Turner, L.D.; Soncini, A.; Murray, K.S. PHI: A Powerful New Program for the Analysis of Anisotropic Monomeric and Exchange-Coupled Polynucleard-And f-Block Complexes. J. Comput. Chem. 2013, 34, 1164-1175. [CrossRef] [PubMed]

35. Pavlov, A.A.; Nelyubina, Y.V.; Kats, S.V.; Penkova, L.V.; Efimov, N.N.; Dmitrienko, A.O.; Vologzhanina, A.V.; Belov, A.S.; Voloshin, Y.Z.; Novikov, V.V. Polymorphism in a Cobalt-Based Single-Ion Magnet Tuning Its Barrier to Magnetization Relaxation. J. Phys. Chem. Lett. 2016, 7, 4111-4116. [CrossRef]

36. Benelli, C.; Caneschi, A.; Gatteschi, D.; Guillou, O.; Pardi, L. Synthesis, Crystal Structure, and Magnetic Properties of Tetranuclear Complexes Containing Exchange-Coupled Dilanthanide-Dicopper (Lanthanide = Gadolinium, Dysprosium) Species. Inorg. Chem. 1990, 29, 1750-1755. [CrossRef]

37. Andruh, M.; Ramade, I.; Codjovi, E.; Guillou, O.; Kahn, O.; Trombe, J.C. Crystal Structure and Magnetic Properties of [Ln2Cu4] Hexanuclear Clusters (Where Ln = Trivalent Lanthanide). Mechanism of the Gadolinium(III)-Copper(II) Magnetic Interaction. J. Am. Chem. Soc. 1993, 115, 1822-1829. [CrossRef]

38. Zhao, Q.H.; Li, L.C.; Liao, D.Z.; Jiang, Z.H.; Yan, S.P.; Fang, R.B. Synthesis and Properties of the Complexes of Lanthanides with Nitronylnitroxidebiradical. Chin. J. Chem. 2000, 18, 561-564.

39. Benelli, C.; Caneschi, A.; Gatteschi, D.; Pardi, L.; Rey, P. Linear-Chain Gadolinium(III) Nitronyl Nitroxide Complexes with Dominant Next-Nearest-Neighbor Magnetic Interactions. Inorg. Chem. 1990, 29, 4223-4228. [CrossRef]

40. Tian, L.; Sun, Y.-Q.; Na, B.; Cheng, P. A Family of Homologous Heterospin Complexes Based on Lanthanides and Biradical Ligands. Eur. J. Inorg. Chem. 2013, 2013, 4329-4335. [CrossRef] 
41. Gupta, T.; Rajeshkumar, T.; Rajaraman, G. Magnetic Exchange in \{Gd(III)-Radical Complexes: Method Assessment, Mechanism of Coupling and Magneto-Structural Correlations. Phys. Chem. Chem. Phys. 2014, 16, 14568-14577. [CrossRef]

42. Ke, H.; Xu, G.F.; Guo, Y.N.; Gamez, P.; Beavers, C.M.; Teat, S.J.; Tang, J. A Linear Tetranucleardysprosium(III) Compound Showing Single-Molecule Magnet Behavior. Chem. Commun. 2010, 46, 6057-6059. [CrossRef] [PubMed]

43. Tian, H.; Zhao, L.; Lin, H.; Tang, J.; Li, G. Butterfly-Shaped Pentanuclear Dysprosium Single-Molecule Magnets. Chem. Eur. J. 2013, 19, 13235-13241. [CrossRef] [PubMed]

44. Lu, J.; Montigaud, V.; Cador, O.; Wu, J.; Zhao, L.; Li, X.-L.; Guo, M.; Le Guennic, B.; Tang, J. Lanthanide(III) Hexanuclear Circular Helicates: Slow Magnetic Relaxation, Toroidal Arrangement of Magnetic Moments, and Magnetocaloric Effects. Inorg. Chem. 2019, 58, 11903-11911. [CrossRef] [PubMed]

45. Liu, C.-M.; Zhang, D.; Zhu, D.-B. Field-Induced Single-Ion Magnets Based on Enantiopure Chiral $\beta$-Diketonate Ligands. Inorg. Chem. 2013, 52, 8933-8940. [CrossRef]

46. Bartolomé, J.; Filoti, G.; Kuncser, V.; Schinteie, G.; Meracre, V.; Anson, C.E.; Powell, A.K.; Prodius, D.; Turta, C. Magnetostructural Correlations in the Tetranuclear Series of $\{\mathrm{Fe} 3 \mathrm{LnO} 2\}$ Butterfly Core Clusters: Magnetic and Mössbauer Spectroscopic Study. Phys. Rev. B. 2009, 80, 014430. [CrossRef]

47. Luis, F.; Bartolomé, J.; Fernandez, J.F.; Tejada, J.; Hernández, J.M.; Zhang, X.X.; Ziolo, R. Thermally Activated and Field-Tuned Tunneling in Mn12Ac Studied by Ac Magnetic Susceptibility. Phys. Rev. B 1997, 55, 11448-11456. [CrossRef]

48. Gatteschi, D.; Sessoli, R. Quantum Tunneling of Magnetization and Related Phenomena in Molecular Materials. Angew. Chem. Int. Ed. 2003, 42, 268-297. [CrossRef]

49. Chilton, N.F.; Collison, D.; McInnes, E.J.L.; Winpenny, R.E.P.; Soncini, A. An Electrostatic Model for the Determination of Magnetic Anisotropy in Dysprosium Complexes. Nat. Commun. 2013, 4, 2551. [CrossRef]

50. Ruamps, R.; Maurice, R.; de Graaf, C.; Guihery, N. Interplay between Local Anisotropies in Binuclear Complexes. Inorg. Chem. 2014, 53, 4508-4516. [CrossRef]

51. Moreno-Pineda, E.; Chilton, N.F.; Marx, R.; Dörfel, M.; Sells, D.O.; Neugebauer, P.; Jiang, S.-D.; Collison, D.; Van Slageren, J.; McInnes, E.J.L.; et al. Direct Measurement of Dysprosium(III) Dysprosium(III) Interactions in a Single-Molecule Magnet. Nat. Commun. 2014, 5, 5243. [CrossRef]

52. Liu, J.-L.; Chen, Y.-C.; Zheng, Y.; Lin, W.-Q.; Ungur, L.; Wernsdorfer, W.; Chibotaru, L.F.; Tong, M.-L. Switching the Anisotropy Barrier of a Single-Ion Magnet by Symmetry Change From Quasi-D5h to Quasi-Oh. Chem. Sci. 2013, 4, 3310-3316. [CrossRef]

53. Bernot, K.; Bogani, L.; Sessoli, R.; Gatteschi, D. [TmIII(hfac)3(NITPhOPh)] $\infty$ : A New Member of a Lanthanide-Based Single Chain Magnets Family. Inorg. Chim. Acta 2007, 360, 3807-3812. [CrossRef]

54. Wang, X.L.; Li, L.C.; Liao, D.Z. Slow Magnetic Relaxation in Lanthanide Complexes with Chelating Nitrony Initroxide Radical. Inorg. Chem. 2010, 49, 4735-4737. [CrossRef] [PubMed]

55. Ullman, E.F.; Call, L.; Osiecki, J.H. Stable Free Radicals. VIII. New Imino, Amidino, and Carbamoy lnitroxides. J. Org. Chem. 1970, 35, 3623-3631. [CrossRef]

56. Ullman, E.F.; Osiecki, J.H.; Boocock, D.G.B.; Darcy, R. Stable Free Radicals. X. Nitronylnitroxidemonoradicals and Biradicals as Possible Small Molecule Spin Labels. J. Am. Chem. Soc. 1972, 94, 7049-7059. [CrossRef]

57. Kahn, O. Molecular Magnetism; VCH: Weinheim, Germany, 1993.

58. Sheldrick, G.M. SHELXS-2014, Program for Structure Solution; Universität of Göttingen: Gottingen, Germany, 2014.

59. Sheldrick, G.M. SHELXL-2014, Program for the Refinement of Crystal Structures; Universität of Göttingen: Göttingen, Germany, 2014.

(C) 2020 by the authors. Licensee MDPI, Basel, Switzerland. This article is an open access article distributed under the terms and conditions of the Creative Commons Attribution (CC BY) license (http://creativecommons.org/licenses/by/4.0/). 